\title{
Performer Telecom Address
}

National Cancer Institute

\section{Source}

National Cancer Institute. Performer Telecom Address. NCI Thesaurus. Code C94271.

A sequence of digits or characters used to identify a particular telephone, fax, or email of the performer. 